
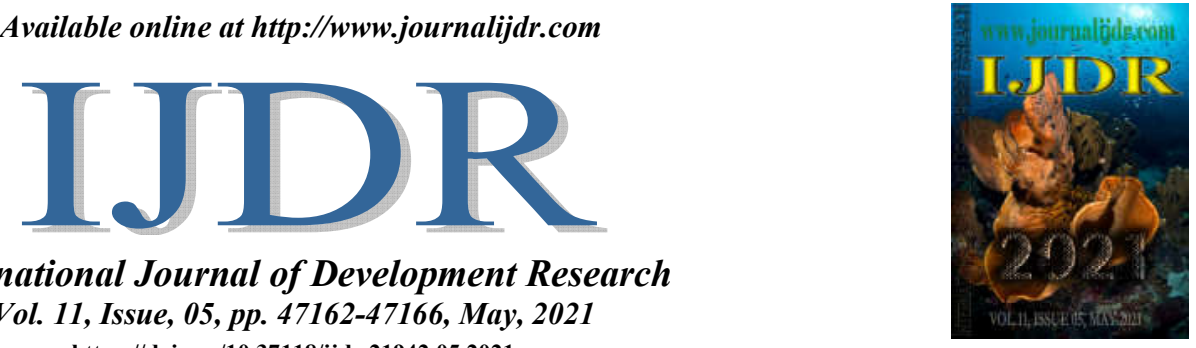

\title{
GESTÃO DE RESÍDUOS SÓLIDOS: ESTUDO DE CASO DE UM PROGRAMA MUNICIPAL DE ECOPONTOS
}

\section{Paulo Wanderson de Sousa Moraes*1 ${ }^{* 1}$ and Mallu de Mendonça Barros ${ }^{2}$}

\begin{abstract}
${ }^{1}$ Discente de Administração de Empresas, Faculdade Sul Americana (FASAM); ${ }^{2}$ Administradora, Doutoranda em Agronegócios, Mestre em Conservação e Preservação do Cerrado (PPGCRENAC-IFGOIANO); Docente Universitária na Faculdade Sul Americana (FASAM) servidora pública lotada na Agência Municipal de Meio Ambiente (AMMA/ Prefeitura de Goiânia)
\end{abstract}

\section{ARTICLE INFO}

\section{Article History:}

Received $11^{\text {th }}$ February, 2021

Received in revised form

$06^{\text {th }}$ March, 2021

Accepted $28^{\text {th }}$ April, 2021

Published online $30^{\text {th }}$ May, 2021

\section{Key Words:}

Ecopoint, Solid waste, Selective collection, Recycling, Ecoponto, Resíduo sólido.

\section{*Corresponding autho:}

Paulo Wanderson de Sousa Moraes

\begin{abstract}
A geração de resíduos sólidos é uma preocupação da sociedade à medida que a população cresce, visto que é diretamente proporcional o quantitativo de resíduos sólidos produzidos. Na cidade de Goiânia, localizado no centro oeste do Brasil, evolução do programa de resíduos sólidos se deu com a implantação dos Ecopontos como resultado das políticas públicas do país e com vistas à preocupação socioambiental, de saúde pública e inovação para se criar novos hábitos na separação do lixo orgânico e reciclável, além de desenvolver novas oportunidades de trabalho e de a inclusão social. Os objetivos deste artigo são: definir o que são os Ecopontos e como funcionam; enumerar as vantagens socioambientais quanto à destinação e descarte correto de resíduos sólidos; descrever como as iniciativas de gestão pública e ambiental que são verificadas em Goiânia; apresentar as forças e as fraquezas do programa de Ecoponto na Gestão da cidade, a partir de um estudo de caso. A pesquisa, por fim, realça a importância de uma política ambientalmente correta e preservação para as futuras gerações, sendo ainda uma forma de contribuir com a educação ambiental.
\end{abstract}

Copyright @ 2021, Paulo Wanderson de Sousa Moraes and Mallu de Mendonça Barros. This is an open access article distributed under the Creative Commons Attribution License, which permits unrestricted use, distribution, and reproduction in any medium, provided the original work is properly cited.

Citation: Paulo Wanderson de Sousa Moraes and Mallu de Mendonça Barros. 2021. "Gestão de resíduos sólidos: estudo de caso de um programa municipal de ecopontos", International Journal of Development Research, 11, (05), 47162-47166.

\section{INTRODUCTION}

Os Ecopontos são locais idealizados para descarte correto de tipos específicos de resíduos, como por exemplo, oriundos da construção civil (cimento, entulho e tijolo, restos de azulejos e madeiras etc); outros resíduos de origem doméstica, como móveis velhos, sobras de poda de árvore e outros materiais volumosos, incluindo-se ainda os recicláveis (papel, papelão, vidro e alumínio), portanto, contentores de grande dimensão com vistas à destinação final ambientalmente adequada de resíduos sólidos. Em outras palavras, as políticas públicas de gestão ambiental têm versado para que se diminuam o despejo desse tipo de material em vias públicas, terrenos baldios ou rios, além de diminuir diversos problemas de saúde e enchentes, e ao se considerar que inciativas como essa possam reduzir os gastos com a limpeza pública. Nesse sentido, os objetivos deste artigo são: definir o que são os Ecopontos e como funcionam; enumerar as vantagens socioambientais quanto à destinação e descarte correto de resíduos sólidos; descrever como as iniciativas de gestão pública e ambiental que são verificadas em Goiânia; apresentar as forças e as fraquezas do programa de Ecoponto na Gestão da cidade, a partir de um estudo de caso. A pesquisa, por fim, realça a importância de uma política ambientalmente correta e preservação para as futuras gerações, sendo ainda uma forma de contribuir com a educação ambiental. Esse estudo visa definir como os Ecopontos atuam produzidos em um município; enumerar as vantagens socioambientais quanto à destinação e descarte correto de resíduos sólidos; descrever como as iniciativas públicas de funcionamento dos Ecopontos tem sido verificadas em Goiânia, considerando-se a necessidade preconizada pela Lei Federal $n^{\circ}$ 12.305/2010 da Política Nacional de Resíduos Sólidos (PNRS); apresentar as forças e as fraquezas verificadas na implantação de um Ecoponto na gestão de resíduos sólidos no município de Goiânia, a partir de um estudo de caso. O presente estudo pretende responder a seguinte questão: a implantação de Ecopontos em Goiânia é resultado das exigências da Política Nacional de Resíduos Sólidos (lei n⿳012.305/2010)? A hipótese é que a obrigatoriedade da lei federal impulsionou a criação dos Ecopontos em Goiânia, além de ser uma demanda da sociedade e esses fatores colaboraram para a implantação dos Ecopontos no município. Ademais, como justificativa social, conhecer as ações governamentais que desenvolvem novas práticas mais resilientes nas cidades e como as população responde à essas iniciativas, sobretudo porque de acordo com Figueiredo, Godecke \& Naime (2012), a partir da década de 1970, junto às ciências econômicas, os debates mundiais impulsionaram os custos e as responsabilidade de um estilo de vida a partir de práticas de consumo consciente para solucionar os problemas ambientais, e que somados à Conferência Rio 92 criou novos ditames no que tange às políticas públicas de destinação de resíduos produzidos junto à implantação de práticas socioambientais 
que gerem trabalho e renda, sem comprometer o meio ambiente e o aumento de espaços que receba esse contingente de resíduos. Isto é, lidar com a diminuição do custo, criar ações de logística reversa, de conscientização ambiental, tanto da separação dos resíduos, quanto da correta destinação para a sua posterior reciclagem.

\section{REVISÃO DE LITERATURA}

Crescimento populacional e suas influências na gestão ambiental: Segundo Figueiredo, Godecke \& Naime (2012), a população do planeta vem aumentando a passos largos, haja vista que ultrapassamos a marca dos sete bilhões, num crescimento de dois bilhões em apenas 25 anos, Besen \& Jacobi (2011), enfatiza que os países precisam adotar a implantação de boas práticas de consumo e produção sustentável e gerenciar adequadamente os resíduos sólidos, reduzindo os impactos à saúde e ao meio ambiente, e de acordo com Figueiredo, Godecke \& Naime (2012), esse pensamento teve início na década de 1970, quando houve grandes discussões econômicas e debates mundiais para que pudesse implementar novas responsabilidades e boas práticas de consumo consciente, o que culminou a Agenda 21, com as metas de proteção dos recursos naturais, na preocupação e suas consequências deu origem ao denominado "consumo verde" e com a ênfase na reciclagem, uso de novas tecnologias limpas e redução do consumo. Para Barbosa \& Ibrahin (2014), a formação da nossa sociedade tem influências sociais, econômicas, políticas e culturais, que precisam considerar o desenvolvimento ambiental, o crescimento populacional ao longo da história, o êxodo rural, a forte competividade industrial e desenvolvimento exagerado, e, portanto, deve-se buscar boas práticas de sustentabilidade. Isso porque segundo Günther (2008), o crescimento urbano gera consigo grandes problemas, como a pobreza, criminalidade, crescimento das favelas, a falta de saneamento ambiental, dificuldade em gestão, ocupação e o uso do solo desenfreado por parte da população, inclusive no Brasil. Enquanto que nos países ricos, produzem uma maior quantidade de resíduos sólidos, há uma melhor capacidade de gestão, pois dentro dessa pragmática incluem fatores econômicos, maior preocupação ambiental e um forte desenvolvimento de novas tecnologias; nos países em desenvolvimento com grande urbanização, há maior dificuldade com défits financeiros e uma administração fraca para o gerenciamento de serviços básicos, como o acesso a água, saneamento, coleta seletiva, segurança e qualidade de vida (BESEN \& JACOBI, 2011).

Ecopontos na cidade de Goiânia: O Programa, os benefícios e as curiosidades de propostas sustentável

Desde 2010, com a implantação da Política Nacional de Resíduos Sólidos (PNRS), novas ações têm contribuído coleta seletiva e a sustentabilidade ambiental, econômica e social. Isso porque nos 5.564 municípios brasileiros, a alteração da palavra "lixo" por "resíduos sólidos" ajudou na compreensão e na distinção entre o que é seco, úmido e rejeitos, ampliou o entendimento que os resíduos podem ser fonte de renda e trabalho, tanto diante à coleta seletiva quanto para a reciclagem (DOURADO; SAIANI; TONETO JÚNIOR, 2014). Sabese que produção de resíduos sólidos urbanos no Brasil é superior a 71,3 milhões de toneladas/ano, sendo aproximadamente $10,2 \%$ sem recolhimento (LOTES et. al., 2018), variando entre 2 a 3\%, sendo que o setor da construção civil demanda de muitos recursos e, além disso, caso não tenha seus resíduos corretamente descartados, gera poluição ambiental (LEITE, 2009) e que, diante da crescente da produção de resíduos sólidos no país e a baixa reciclagem de alguns tipos de resíduos, iniciativas e ideias como o Projeto Ecoponto popularizam a sensibilização da sociedade ao propor prática de redução, reutilização e reciclagem de seus resíduos, e do destino correto de resíduos sólidos (LOPES et. al., 2018). Conforme o Plano de Coleta Seletiva de Goiânia (PCSG, 2012), "Ecoponto são locais de entrega voluntária de pequenos volumes de entulho (até $1 \mathrm{~m}^{3}$ ), grandes objetos (móveis, restos de poda de árvores etc.) e resíduos recicláveis além de pneus que são gerados pela população civil". O Ecoponto tem como principais objetivos: oferecer à população um local adequado para entregar voluntariamente outros tipos de resíduos que a coleta seletiva não recolhe ou de resíduos recicláveis em momento alternativo à coleta seletiva formal; diminuir a quantidade de pontos de descarte irregular; auxiliar no aumento de níveis de reciclagem do município (PREFEITURA DE GOIÂNIA, 2012). Dentre os benefícios para a população, há o aumento da percepção ambiental, do senso de responsabilidade e coparticipação em prol de uma conduta ecologicamente responsável, tanto pela iniciativa da administração pública quanto pela munícipes, pois estes podem dispor do material de forma gratuita em caçambas distintas para cada tipo de resíduo (CAMPOS, MALHEIROS \& SILVA, 2013); a relevância se verifica também na questão de sustentabilidade ambiental diante à redução da emissão dos gases do efeito estufa, que são os causadores da mudança climática por conta de gases como o metano; da erradicação da pobreza, como atendimento de outro item dos objetivos de desenvolvimento sustentável previstos pela ONU.

De acordo com a lei $\mathrm{n}^{\circ}$ 12.305/2010 da Política Nacional de Resíduos Sólidos (PNRS) no Art. 18 se tornou obrigatória a elaboração do Plano de Gestão Integrada de Resíduos Sólidos (PGIRS) como condição para o Distrito Federal e os Municípios terem acesso a recursos da União, que são destinados a serviços relacionados a limpeza urbana, bem como ao manejo de resíduos sólidos. Sendo necessário ainda mecanismos para redução, reutilização, coleta seletiva e reciclagem, dentre outras, visando a redução da quantidade de rejeitos encaminhados para disposição final ambientalmente adequada. Ou seja, os Pontos de Entrega Voluntaria (PEV) ou Ecopontos surgiram em virtude dessas exigências como mecanismo para criação de fontes de negócios, emprego e renda, mediante a valorização dos resíduos sólidos. As perspectivas de implantação de um Ecoponto incluem as seguintes ações: Oferecer à população um local adequado para entregar voluntariamente outros tipos de resíduos que a coleta seletiva não recolhe ou de resíduos recicláveis em momento alternativo à coleta seletiva formal; Diminuir a quantidade de pontos de descarte irregular; Pode auxiliar no aumento de níveis de reciclagem do município. (PCSG, 2012), sendo ensejador para quem em Goiânia, a prefeitura tivesse investido na implantação de dois Ecopontos.

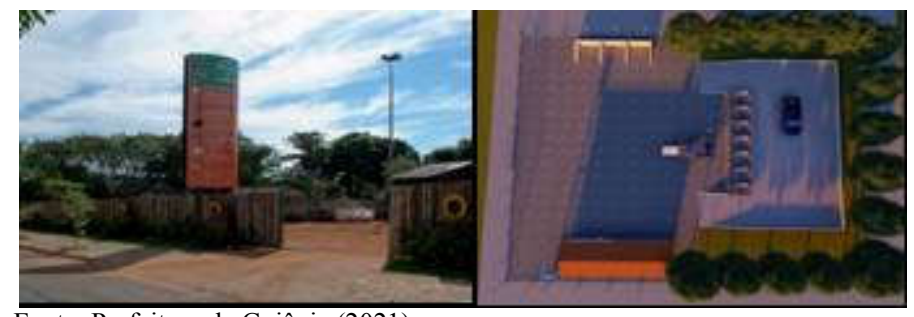

Fonte: Prefeitura de Goiânia (2021)

Figura 1. Ponto de Entrega de Resíduos Sólidos - Programa de Ecopontos de Goiânia

De acordo com a Prefeitura de Goiânia (2020), "O Ecoponto, com apenas em seis meses de funcionamento, recebeu mais de 600 toneladas de resíduos recicláveis, construção civil e galhos, demostrando assim a sua funcionalidade e o interesse da população para o descarte correto, nesse mesmo período foram recebidos mais de 700 pneus inservíveis. Ou seja, o controle dos resíduos é proporcionado direta e indiretamente com a existência desse tipo de infraestrutura feita pela administração pública e conscientizando a população através de conceitos como os 3R's: reciclar, reduzir e reutilizar, sendo possível a eliminação de forma sustentável, sendo possível a sua utilização em algo novo. O quadro 1, apresenta os tipos de resíduos sólidos que devem sua destinação correta, incluindo aqueles que irão para o Ecoponto. Além de orientar, informar e esclarecer da existência desses locais e despertar o entendimento da sociedade sobre essa adequada gestão de resíduos sólidos, no município de Goiânia. Infere-se do quadro 1, como se procede a destinação correta dos entulhos como: telhas, azulejos, tijolos, pedaços de pisos (pedra ou cerâmica), pedaços de cimento e concreto e outros objetos e materiais que sejam resto de obras ou construções. 


\section{Quadro 1. Ecoponto e a Destinação correta de Resíduos Sólidos. O que pode ou não ser destinado a um Ecoponto}

\begin{tabular}{|c|c|}
\hline PODE SER DESCARTADO NO ECOPONTO & NÃO DESCARTADO NO ECOPONTO \\
\hline $\begin{array}{l}\text { - Resíduos da construção civil: tijolos, blocos, telhas, placas de revestimento, } \\
\text { argamassa, concreto e outros; } \\
\text { - Materiais recicláveis: plástico, papel, papelão, metal, vidro, madeira, } \\
\text { embalagens vazias de tintas imobiliárias, gesso, entre outros; } \\
\text { - Pneus inservíveis: até quatro unidades por dia; } \\
\text { - Poda de galhos, folhas, capim, entre outros provenientes da limpeza } \\
\text { particular, no total até } 2 \mathrm{~m}^{3} \text {, volume equivalente a um reservatório de água de } \\
2.000 \text { litros; } \\
\text { - Objetos gerados nas residências denominados como móveis, eletrodomésticos } \\
\text { e seus componentes. Até quatro unidades por dia. }\end{array}$ & $\begin{array}{l}\text { - Restos de alimentos, rejeito sanitário, entre outros; } \\
\text { - Tecnologias que não permitam reciclagem como televisores e similares; } \\
\text { - Resíduos de construção, como tintas, solventes, óleos e outros; } \\
\text { - Resíduos de serviço de saúde, como órgãos, tecidos, radioativos, } \\
\text { perfurocortantes, entre outros. } \\
\text { - Resíduos industriais; } \\
\text { - Resíduos agrícolas e da pecuária, como fertilizantes, defensivos, rações, } \\
\text { entre outros; } \\
\text { - Resíduos perigosos a exemplo de lâmpadas, pilhas e baterias, eletrônicos, } \\
\text { entre outros. }\end{array}$ \\
\hline
\end{tabular}

Fonte: Prefeitura de Goiânia (COMURG, 2020). Adaptado pelos autores (2021)

Quadro 2. A caracterização dos tipos de resíduos e exemplificação dos itens coletados pelo Ecoponto de Goiânia

\begin{tabular}{|l|l|}
\hline Caracterização de Resíduos & Exemplos de Resíduos Recebidos no Ecoponto Goiânia \\
\hline Resíduos Volumosos & Móveis, geladeiras, fogões e colchões. \\
\hline Resíduos da Construção Civil / Resíduos de Construção e Demolição & Tijolos e telhas, em especial dos geradores de pequenos volumes. \\
\hline Resíduos de Madeira & Pallets, briquetes, adubos orgânicos, lenha. \\
\hline Óleo de Cozinha & Origem animal e vegetal. \\
\hline Pneus & Pneus de todos os tipos e tamanhos. \\
\hline Podas de Arvores e Outros Resíduos Verdes & $\begin{array}{l}\text { Galhos, troncos, ramos mortos, danificados, doentes ou praguejados; } \\
\text { remover partes da árvore. }\end{array}$ \\
\hline Resíduos Recicláveis & Plástico, papel, isopor, metais, arames e vidros. \\
\hline Fonte: Os autores (2021) [Adaptado PCSG, 2012] & \\
\hline
\end{tabular}

São proibidos dos descartes de: lixo convencional como dejetos orgânicos, e recicláveis - e plástico, papel e alumínio, ou seja, àquilo que não se enquadra como resultado de obras ou de construção. Desde 2012 a prefeitura de Goiânia tem editado o Plano de Coleta Seletiva de Goiânia (PCSG, 2012, p.81), que prevê das áreas de descarte de resíduos através de Ecopontos; as áreas para desenvolvimento das concepções dos projetos, conforme o quadro 2, na tentativa de resolver os problemas como os resíduos da construção civil que são responsáveis pela imensa quantidade de resíduos gerados no mundo e que, no Brasil representam $67 \%$ dos resíduos sólidos urbanos municipais e gerou cerca de 150 milhões de toneladas de resíduos em 2014, devido a ausência prática de programas e políticas de incentivo ou leis que punam transgressores e empresas deste segmento (MARCHESINI \& SANTOS, 2018). Nesse contexto, as ações, os planos e as estratégias de Educação Ambiental, têm atuado no sentido de atender o Plano Nacional de Resíduos Sólidos PNRS - em que os governos e instituições promovem informações orientadoras objetivando a sensibilização, a participação popular e a mobilização das comunidades envolvidas nos sistemas de gestão de resíduos, bem como promoção da sensibilização e envolvimento das comunidades escolares e campanhas especificas de divulgação de serviços, como se verifica no Plano de Coleta Seletiva em Goiânia e outros municípios brasileiros.

\section{METODOLOGIA}

Este é um estudo estruturado em duas etapas: i) revisão da literatura, por ser uma pesquisa descritiva que foi capaz de identificar e descrever as características de determinada população, indivíduo, local, máquina, empresa ou fenômeno ou o estabelecimento de relações entre variáveis (FRACASSI et al. (2013) e exploratória, porque foi resultado da formulação de questões problema, para aumentar a familiaridade do pesquisador com um ambiente, fato ou fenômeno (MARCONI \& LAKATOS, 2003), ii) pesquisa de campo, que usou o método qualiquantitativo, para a obtenção das informações e/ou conhecimentos acerca de um problema para o qual procuramos uma resposta e descobrir os fenômenos decorrentes das relações verificadas (PRODANOV; FREITAS (2013). Na $1^{\text {a }}$ etapa ocorreu a revisão e o levantamento da bibliografia, e este estudo consultou artigos periódicos CAPES e Google Acadêmico, mediante palavras chaves "Ecoponto", "Resíduos Sólidos", "Meio Ambiente" e "Gestão Ambiental", consultando a literatura relacionado a temática, pelos métodos exploratórios. $\mathrm{Na} 2^{\mathrm{a}}$ etapa, foi realizada uma pesquisa de campo - Para isso, foi realizada entrevistas com gestores públicos sobre a implantação de Ecopontos em Goiânia -entre os meses de março a abril de 2021 - que foram respondidas pelo "Google Formulários", de forma online, por conta da pandemia do SarsCov-2 (Covide-19), e para o atendimento dos objetivos deste estudo. Para a tabulação e tratamento de dados, realizou-se o uso de software do Google Formulários e do Excel, pacote do Microsoft Office e do software estatístico R e Iramuteq para elaboração dos gráficos de similitude.

\section{RESULTADOS}

A pesquisa de campo contou com entrevista a 7 gestores públicos responsáveis direto e indiretamente pela implantação e gestão dos Ecopontos do município de Goiânia. Ao se caracterizar o perfil dos gestores, obteve-se como resultado: todos relataram possuir idades compreendidas na faixa etária entre 41 e 50 anos; quanto ao gênero, 4 homens e 3 mulheres; quanto à formação escolar, apesar de diversa, deve ocorrer no âmbito da prefeitura algum estímulo para a formação continuada dos gestores ou metas para a diversificação de programas e políticas públicas, obteve-se como resultado dessa investigação que inclusive uma parcela de gestores detém afinidade pesquisa científica por conta da formação stricto sensu.

O quadro 3, apontou os fatores resultantes da implantação do Programa de Ecopontos de Goiânia, sendo constatado, os aspectos das demandas históricas, sociais e legais como definidoras para que o município de Goiânia e impactasse a população goianiense por um novo viés socioambiental e, verificou-se com base na análise de similitude, que a ênfase da governança e foi destacada na figura diante a integração do sistema de blocos comprometidos, ou seja, como os fatores estratégicos e as competências estão relacionadas à implementação do Programa do Ecoponto em Goiânia, como se verifica na Figura 1. O grafo de similitude apresenta quatro blocos ligados, diretamente comprometidos, a partir do termo resíduos e o grau de importância estratégica para a Administração Pública nas competências relacionadas a implementação ao Ecoponto, quanto as questão de prática ambiental; melhoria; saúde; impacto; público; diminuição; gasto; sólido; urbano; área; ecoponto; vantagem; descarte; adequado; ser - a figura 2, traduz, com base no resultado das respostas dos 7 entrevistados, os principais pontos em comum que corroboram com o Art. 19 da Política Nacional de Resíduos Sólidos em que o governo municipal detém sinergia quanto a elaboração do programa dos Ecopontos e de ações de educação ambiental que promovam os $3 R$ 's: redução, a reutilização e a reciclagem de resíduos sólidos. 


\section{Quadro 3. Quantidade e Razões que levaram a Prefeitura de Goiânia a implantação dos Ecopontos}

\begin{tabular}{|c|c|c|}
\hline Coleta & $\begin{array}{l}\text { ASPECTOS CONSIDERADOA PARA A IMPLANTAÇÃO: HISTÓRIA, } \\
\text { CULTURA E SOCIEDADE. }\end{array}$ & FATOR DE IMPACTO \\
\hline Entrevistado_1 & $\begin{array}{l}\text { Antes da implantação do Programa de Ecopontos, a população associava apenas a } \\
\text { ideia de lixões a céu aberto; somente após a PNRS - Lei 12.305/2010 começou a ser } \\
\text { articular a implantação desses pontos de descartes, bem como a conscientização da } \\
\text { população da correta destinação desses resíduos. }\end{array}$ & $\begin{array}{l}\text { Ter } 02 \text { Ecopontos capazes de eliminar a } \\
\text { imagem de lixões a céu aberto. }\end{array}$ \\
\hline Entrevistado_2 & $\begin{array}{l}\text { Conta com } 02 \text { Ecopontos instalados desde } 2018 \text {, iniciou-se com os PEVs e então } \\
\text { optou-se por uma estrutura maior que abrigassem os Resíduos de Construção Civil } \\
\text { (RCC), visto da necessidade de atender o pequeno gerador deste tipo de resíduo de } \\
\text { acordo com a PNRS - Lei } 12.305 / 2010 \text {. }\end{array}$ & $\begin{array}{l}\text { Os Ecopontos iniciam os pontos de coleta } \\
\text { (PEVs) como estruturas de maior porte para } \\
\text { atender a PNRS. }\end{array}$ \\
\hline Entrevistado_3 & $\begin{array}{l}\text { Análise, Estudo e Definição dos bairros para a implantação dos Ecopontos de } \\
\text { Goiânia. Novo Ecoponto: Setor São José. }\end{array}$ & $\begin{array}{l}\text { Goiânia prevê até o final do Ano de } 2021 \text { ter } 3 \\
\text { Ecopontos ativos. }\end{array}$ \\
\hline Entrevistado_4 & $\begin{array}{l}\text { Implantação e necessidade de disponibilizar para a população um local de descarte } \\
\text { correto dos resíduos sólidos urbanos (RSU), antes descartados de forma irregular e } \\
\text { em áreas inapropriadas, o que culminou no desenvolvimento do projeto. }\end{array}$ & $\begin{array}{l}\text { Criação de locais adequados de descarte de } \\
\text { RSU e ampliação e desenvolvimento deste } \\
\text { projeto. }\end{array}$ \\
\hline Entrevistado_5 & $\begin{array}{l}\text { Redução de descarte clandestino de RSU; formas de atender a implementação da } \\
\text { PNRS - Lei } 12.305 / 2010 \text {. }\end{array}$ & $\begin{array}{l}\text { Possui } 03 \text { Ecopontos / Colabora para redução } \\
\text { de descarte de RSU / Atender a PNRS. }\end{array}$ \\
\hline Entrevistado_6 & $\begin{array}{l}\text { Estudo e Definição dos bairros para a implantação: Setor São José, Setor Faiçalville } \\
\text { e Jardim Guanabara. }\end{array}$ & $\begin{array}{l}\text { Demanda pública e social para Implantação de } \\
\text { Ecopontos. }\end{array}$ \\
\hline Entrevistado_7 & $\begin{array}{l}\text { Estudo e Definição dos bairros para a implantação: Setor São José, Setor Faiçalville } \\
\text { e Jardim Guanabara. }\end{array}$ & $\begin{array}{l}\text { Demanda pública e social para Implantação de } \\
\text { Ecopontos. }\end{array}$ \\
\hline
\end{tabular}

Fonte: Os autores (2021)

Como resultado da pesquisa, obteve-se que os desafios e potenciais fraquezas verificadas na política pública que implantou o Ecoponto em Goiânia, estão relacionadas a encontrar áreas disponíveis e adequadas para instalação dos Ecopontos, da aceitação da comunidade local e dos recursos financeiros disponíveis para implementação do programa.

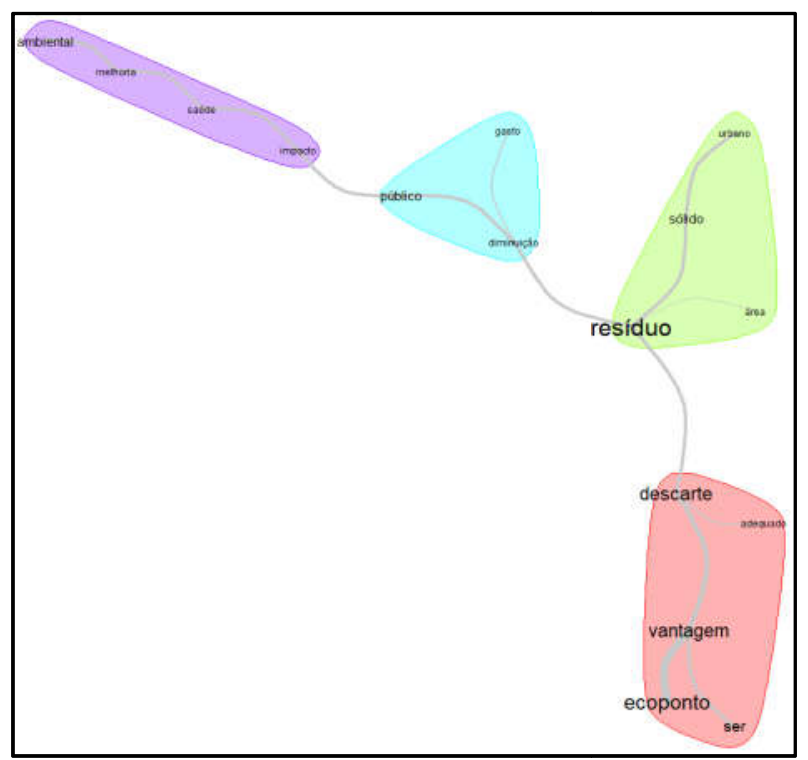

Fonte: Os autores (2021)

Figura 1. Grafo de similitude das vantagens socioambientais de um Ecoponto em Goiânia: uma análise dos gestores públicos (Ano Referência: 2021)

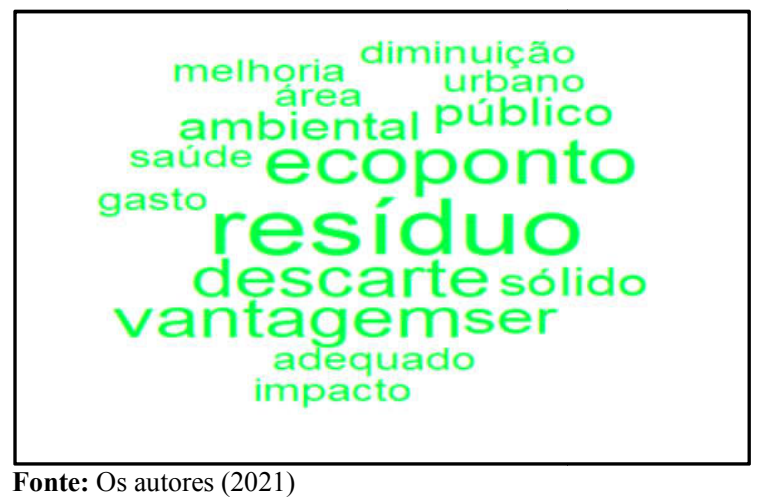

Figura 2. Nuvem de Palavras da análise da governança quanto às vantagens socioambientais de um Ecoponto para a população goianiense
Essa dificuldade de instalação adequada da infraestrutura necessária pode ser resultado a dificuldade que os municípios têm dos recursos oriundos da União, previstas na Lei $\mathrm{n}^{\circ} 12.305 / 2010$, determina que para implantação de políticas públicas ambientais ou para a manutenção de serviços relacionados a limpeza urbana e o manejo dos resíduos sólidos é preciso a aceitação da comunidade daquela região circunvizinha, o que requer o envolvimento dos poderes públicos com outras instituições públicas e privadas, com ou sem fins lucrativos, no desenvolvimento de práticas educativas voltadas a sensibilização da coletividade sobre questões ambientais (MARTINS; MORAES \& TEIXEIRA, 2012). Diante desses resultados de forças e fraquezas observados na implantação e manutenção dos Ecopontos, pode verificar a seguinte matriz SWOT, abaixo:

Quadro 4. Análise SWOT - Forças e Fraquezas de Programa de Eco Ponto em Goiânia (Período em Análise: 2021)

\begin{tabular}{|c|c|c|}
\hline \multirow[b]{2}{*}{ 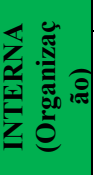 } & FORÇAS (S) & FRAQUEZAS (W) \\
\hline & $\begin{array}{l}\text { - Melhoria da saúde pública; } \\
\text { - Descarte ambientalmente } \\
\text { adequado; } \\
\text { - Participação da população. }\end{array}$ & $\begin{array}{l}\text { - Obtenção de áreas } \\
\text { adequadas; } \\
\text { - Aceitação da população; } \\
\text { - Recursos financeiros. }\end{array}$ \\
\hline \multirow[b]{2}{*}{ 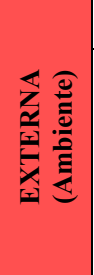 } & OPORTUNIDADES (O) & AMEAÇAS (T) \\
\hline & $\begin{array}{l}\text { - Participação das cooperativas de } \\
\text { reciclagem; } \\
\text { - Acordos setoriais com o comercio, } \\
\text { fornecedores e indústrias; } \\
\text { - Parcerias públicas para Logística } \\
\text { Reversa de pilhas, baterias, pneus } \\
\text { etc. }\end{array}$ & $\begin{array}{l}\text { - Vandalismo; } \\
\text { - Coleta seletiva porta-a- } \\
\text { porta; } \\
\text { - Programa cata treco. }\end{array}$ \\
\hline
\end{tabular}

Fonte: Os autores (2021)

São resultados da pesquisa, conforme quadro 4: Forças(S): melhoria da saúde pública; descarte ambientalmente adequado e participação da população. Justificando o objetivo do PMGIRS de Goiânia, que ao ser descartado corretamente os resíduos, elimina os criadores de doenças como a dengue e chicungunha sendo de total importância pra saúde da população goianiense.; Fraquezas (W): obtenção de áreas adequadas, aceitação da população e recursos financeiros. Em comparação a outras cidades como fortaleza que já contam com mais de 70 Ecopontos é preciso a adoção de práticas semelhantes que possam sensibilizar a população sobre a importância da instalação dos Ecopontos; Oportunidades (O): participação das cooperativas de reciclagem, acordos setoriais com o comercio, fornecedores $\mathrm{e}$ indústrias, parceirinhas públicas para logística reversa de pilhas, baterias, pneus etc. Buscando fortalecer o programa Ecopontos é de grande importância a participação conjunta de todos esses agentes envolvidos, ou seja a responsabilidade compartilhada do programa, partindo do poder público essa iniciativa, visto a importância da 
logística reversa, pois o município ainda não conta com essa política ambiental; Ameaças (T): vandalismo, coleta seletiva porta-a-porta, programa cata-treco. O programa coleta seletiva porta-a-porta instituído antes da promulgação da PNRS sendo disponível em 100\% dos bairros e o cata-treco sendo agendado a sua retirada se torna uma ameaça ao desenvolvimento do programa Ecopontos, visto a sua maior aceitação pela população goianiense. $\mathrm{O}$ vandalismo é outra grande ameaça ao programa, sendo possível constatar isso na implantação dos mais de 100 PEVs, no início de 2008, sofreram depredações enquanto patrimônio público municipal.

\section{CONCLUSÃO}

Os Ecopontos são uma resposta de gestão ambiental, diante do agravamento do aumento do consumo e da produção de resíduos, visto que apenas reciclar não resolve o problema da destinação correta e da conscientização social, estes contentores de grande dimensão são estratégias de gestão pública ambientalmente adequadas quanto montante de resíduos sólidos que são produzidos numa capital, como Goiânia. Constatou-se que as demandas sociais, históricas e legais influenciam diretamente na implantação de um programa de destinação de resíduos sólidos e de políticas de gestão pública adequadas, ensejando maior aceitação das práticas resilientes ao meio ambiente e criando na população uma coparticipação decisória que, implica, inclusive na formação de novas cadeias de trabalho e renda, como a dos catadores de materiais recicláveis, e, por fim, ser uma estratégia adicional à coleta seletiva existente no município.

\section{Conflito de interesses}

Os autores deste estudo negam qualquer tipo de conflito de interesses sobre a produção e publicação da pesquisa.

\section{REFERÊNCIAS}

BARBOSA, R. P.; IBRAHIN, F. I. D. Resíduos Sólidos: Impactos, Manejo e Gestão Ambiental. 1. ed. São Paulo: Érica, 2014. Disponível em: <biblioteca online da faculdade FASAM>. Acesso: 21. nov. 2020.

BESEN, G. R.; JACOBI, P. R. Gestão de Resíduos Sólidos em São Paulo: Desafios da Sustentabilidade. São Paulo: Instituto de Estudos Avançados da USP, 2011. Disponível em: $<$ https://www.scielo.br/pdf/ea/v25n71/10>. Acesso: 21 de nov. de 2020.
CAMPOS, C. A.; MALHEIROS, R.; SILVA, N. C. A Reciclagem e o Destino Final dos Resíduos Sólidos de Construção e Demolição Produzidos no Município de Goiânia. Salvador: IBEAS, 2013. Disponível em: <http://www.ibeas.org.br/congresso/ Trabalhos2013/III-034.pdf>. Acesso: 23. nov. 2020.

DOURADO, J.; SAIANI, C. C. S.; TONETO JÚNIOR, R. Resíduos Sólidos no Brasil: Oportunidades e Desafios da Lei Federal $n^{\circ}$ 12.305 (Lei de Resíduos Sólidos). 1. ed. Barueri: Minha Editora, 2014. Disponível em: <biblioteca virtual da faculdade FASAM>. Acesso: 21. nov. 2020.

FIGUEIREDO, J. A. S.; GODECKE, M. V.; NAIME, R. H. O Consumismo e a Geração de Resíduos Sólidos Urbanos no Brasil. Santa Maria: REGET, 2012. Disponível em: $<$ https://periodicos.ufsm.br/index.php/reget/article/view/6380>. Acesso: 21. nov. 2020.

FRACASSI, M. A. T.; MÜLlER, D. M.; ROMEIRO, S. B. B.; SOUZA, D. I. Manual de Orientações para Projetos de Pesquisa. Novo Hamburgo: FESLSVC, 2013.

GüNTHER, W. M. R. Resíduos Sólidos no Contexto da Saúde Ambiental. São Paulo: USP, 2008. Disponível em: $<$ https://www.teses.usp.br/teses/disponiveis/livredocencia/6/tde19072010-144112/en.php>. Acesso: 21. nov. 2020.

LEITE, P. R. Logística Reversa: Meio Ambiente e Competitividade. 2. ed. São Paulo:

LOPES, P. F. M.; LOPES, R. F. N.; JÚNIOR, F. S. N.; MEDEIROS, P. I. S.; SANTOS, R. A Implantação e um Ecoponto de Resíduos de Difícil Reciclagem como Estratégia pra a Sensibilização da Comunidade Universitária. Rio Grande do Norte: UFRN, 2018. Disponível em: <https://www.researchgate. net/publication/331305712_A_IMPLANTACAO_DE_UM_EC OPONTO DE RESIDUOS $\bar{D}$ E DIFICIL RECICLAGEM $\overline{C O}$ MO_ESTRATEGIA_PARA_A_SENSIBILIZACAO_DA_COM UNIDADE_UNIVERSITARIA $>$. Acesso: 01. abr. 2021.

MARCHESINI, M. M. P.; SANTOS, M. H. S. Logística Reversa para a Destinação Ambientalmente Sustentável dos Resíduos de Construção e Demolição (RCD). São Paulo: RMS, 2018. Disponível em: <https://revistaseletronicas.fmu.br/index.php/ rms/article/view/1359>. Acesso: 01. abr. 2021.

MARCONI, M. A.; LAKATOS, E. M. Fundamentos de Metodologia Científica. 5. ed. São Paulo: Editora Atlas, 2003.

MARTINS, L. A.; MORAES, C. M. L.; TEIXEIRA, A. B. A Educação Ambiental, Por Meio da Arte Educação, Para Ampliação da Coleta Seletiva no Setor Aeroporto em Goiânia GO. Goiânia: IBEAS, 2012. Disponível em: $<$ http://www.ibeas.org.br/congresso/Trabalhos2012/VII016.pdf>. Acesso: 11. maio. 2021.

Pearson Prentice Hall, 2009. ISBN 978-85-7605-365-1.

PRODANOV, C. C.; FREITAS, E. C. Metodologia do Trabalho Científico: Métodos e Técnicas da Pesquisa e do Trabalho Acadêmico. 2. ed. Novo Hamburgo: FEEVALE, 2013. 